\title{
Direct Shear Test Analysis of Coarse-grained Soil in Nyang River Valley Based on Dynamic Shear Area
}

\author{
Ruijie Lin ${ }^{1, a}$, Zhixiang Cao ${ }^{1,2, b, *}$, Xinwei Song ${ }^{1, c}$, Suhua Zhao ${ }^{1, d}$, Xiandong Han ${ }^{1, e}$ \\ ${ }^{1}$ Department of Water Conservancy and Civil Engineering, Tibet Agricultural and Animal Husbandry \\ College, Linzhi, Tibet 86000, China \\ ${ }^{2}$ State Key Laboratory of Hydrology-Water Resources and Hydraulic Engineering, Nanjing, Jiangsu 210098, \\ China \\ a1271269574@qq.com, b caozhx2005@126.com, c 422978746@qq.com, ${ }^{d}$ 1442313722@qq.com, \\ e1637555989@qq.com
}

Keywords: Nyang River Valley, coarse-grained soil, direct shear test, dynamic shear area, shear stress correction

\begin{abstract}
The shear strength of coarse-grained soil is usually measured through a large-scale direct shear test. However, the dynamic change of the shear surface during the test has an effect on the calculation of the shear strength of coarse-grained soil. This paper put forward the formula for the dynamic shear area, determined the dynamic shear area of the DHJ50-2 type superimposed ring shear test machine with the formula and carried out error analysis. In this paper, the shear strength tests of four kinds of homogeneous coarse-grained soils with different particle sizes in Nyang River Valley were carried out, and the shear strength was corrected with the dynamic shear area. The results showed that, for the DHJ50-2 type superimposed ring shear test machine, there was $15.10 \%$ error between the shear area with maximum shear displacement and the unchanged one; both the peak shear stress and internal friction angle of four kinds of coarse-grained soil were higher after correction while the cohesiveness of most coarse-grained soil decreased; and after correction, the peak shear stress of most samples was backward with the shear displacement.
\end{abstract}

\section{Introduction}

Coarse-grained soil is a natural building material with wide distribution, rich reserves and good engineering performance ${ }^{[1]}$. The sandstone gravels are mostly distributed in the southeast of Tibet, and the foundation of hydraulic engineering, regional roads, and roadbeds for houses as well as slope protection and treatment projects are all based on coarse-grained soils. The accuracy of shear strength is directly related to the safety, economy and rationality of engineering design and construction $^{[2]}$. Therefore, the accurate determination of shear strength is particularly important. Direct shear test and triaxial test are common methods for measuring the shear strength of coarsegrained soil. The direct shear test is widely used in scientific research and engineering due to its simple principle, convenient operation, and low $\operatorname{cost}^{[3-7]}$. In Chinese current 《Specification of Soil Test》(SL 237-1999) ${ }^{[8]}$, the shear area keeps constant during the direct shear test. However, during the direct shear test, as the shear displacement increases, the upper and lower shear boxes are shifted and the effective area of the sheared soil is dynamically reduced. The constant shear area treatment has certain influence on the ultimate shear strength. Some researchers have also pay attention to the dynamic change of the effective shear area during the direct shear test ${ }^{[2,3,9-12]}$. The author put forward the effective shear area formula with the dynamic change of shear displacement through two parameters, including shear displacement and shear box diameter. The effective shear area of the DHJ50-2 ring shear tester was dynamically determined, and shear strength tests were performed on four single-grained coarse-grained soils collected from the YarluZangbu River-Nyang River Valley, and corrected shear strength was analyzed by comparing to the uncorrected one. 


\section{Direct Shear Test Principle and Dynamic Shear Area Formula}

\subsection{Direct Shear Test Principle}

The direct shear test acts on the soil through the shear plane in the horizontal direction. The test principle is shown in Figure 1.

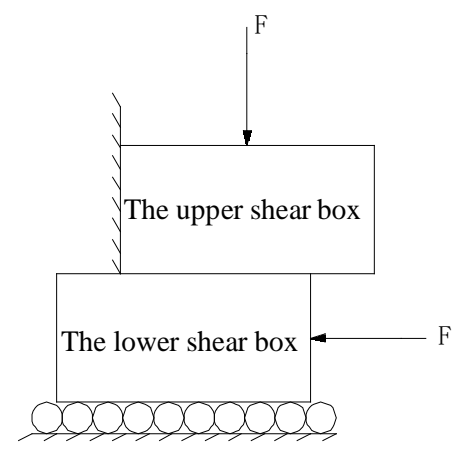

Figure 1 Schematic diagram of direct shear test.

The shear strength of the soil is calculated with the Mo-hr-Coulomb formula:

$$
\tau=c+\sigma \operatorname{tg} \phi
$$

In the formula: $\tau$-Soil shear strength (kPa),$\sigma$-Normal stress acting on the shear surface of the soil $(\mathrm{kPa}),{ }^{\phi}$-Friction angle of the soil $\left(^{\circ}\right),{ }^{c}$-Cohesion of the soil (Coarse-grained soil is called bite force or structural force) (kPa).

\subsection{Dynamic Shear Area Calculation Formula}

The dynamic change of the shear plane during direct shear test is shown in Figure 2, which is the horizontal projection of Figure 1. During the test, the upper shear box is fixed in the horizontal direction. At the beginning of the test, the lower shear box has not yet been displaced, and the upper and lower shear boxes overlap with a circular shear plane. As the experiment continues, the lower scissor box is gradually moved, the upper and lower scissor boxes are staggered, and the shear plane becomes the intersecting area of two circles, which is the non-shaded portion in Figure 2. When the shear displacement is large, the change of shear area is considerable. If the shear strength of the soil sample is calculated with the initial area, there will be an error.

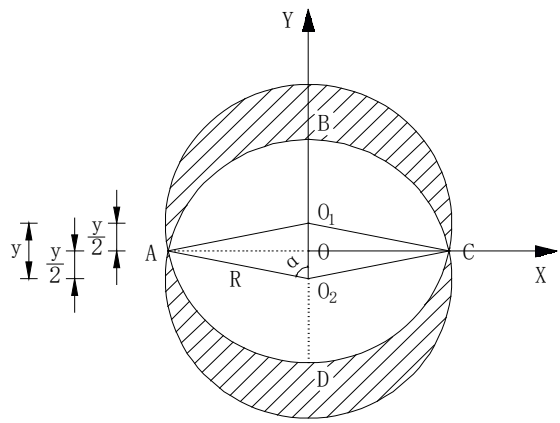

Figure 2 Diagram of dynamic change of shear area in direct shear test.

In order to eliminate the error caused by the unreal shear area, the shear area calculation formula of the dynamic change is derived as follows in combination with Figure 2:

In Figure 2, $\mathrm{y}$ is the horizontal displacement of the lower scissor box, $\mathrm{R}$ is the radius of the upper and lower scissor box, and the non-shaded part in Figure 2 is the dynamic shear plane, that is $S_{A B C D}$. $S_{\mathrm{AO}_{2} \mathrm{~B}}$ is a sector and ${ }^{\mathrm{AO}_{1} \mathrm{O}_{2}}$ is a triangle.

From the area relationship in Figure 2, it can be seen:

$$
\begin{array}{r}
S_{A B C D}=4 S_{A O_{2} B}-2 S_{A O_{1} O_{2}} \\
\alpha=\arccos \frac{y}{2 R}
\end{array}
$$


The area of the sector ${ }^{\mathrm{AO}_{2} \mathrm{~B}}$ :

$$
S_{\mathrm{AO}_{2} \mathrm{~B}}=\frac{\alpha}{360^{0}} \pi R^{2}
$$

Substitute equation (3) into equation (4):

$$
S_{\mathrm{AO}_{2} B}=\frac{\arccos \frac{y}{2 R}}{360^{0}} \pi R^{2}
$$

Use Helen formula to find the triangle area:

$$
S_{\mathrm{AO}_{1} \mathrm{O}_{2}}=\sqrt{P(P-a)(P-a)(P-a)}
$$

In the triangle ${ }_{\mathrm{AO}_{1} \mathrm{O}_{2}}$ :

$$
\begin{aligned}
a=R, b & =R, c=y \\
P & =\frac{a+b+c}{2}
\end{aligned}
$$

Substitute (7) and (8) into (6):

$$
S_{A O_{1} \mathrm{O}_{2}}=\frac{y}{2} \sqrt{R^{2}-\frac{y^{2}}{4}}
$$

Substitute (5) and (9) into (2):

$$
S_{A B C D}=\frac{\arccos \frac{y}{2 R}}{360^{0}} 4 \pi R^{2}-y \sqrt{R^{2}-\frac{y^{2}}{4}}
$$

Equation (10) is the calculation formula of the dynamic shear area of the soil sample during the direct shear test.

\section{Dynamic Shear Area Calibration and Error Analysis of DHJ50-2 Stacked Shear Tester}

The test adopts DHJ50-2 Stacked Shear Tester with the maximum allowable shearing displacement $60 \mathrm{~mm}$, and the sample size is $\Phi 504.6 \mathrm{~mm} \times \mathrm{H} 400 \mathrm{~mm}$, . The dynamic shear area of the testing machine is calibrated with equation (10). The calculation results are shown in Table 1.

Table 1 Dynamic change rate of shear area with shear displacement of DHJ50-2 type superimposed ring shear test machine.

\begin{tabular}{ccc}
\hline Shear displacement $\mathrm{y} / \mathrm{mm}$ & Dynamic shear area $/ \mathrm{mm}^{2}$ & The proportion in the initial area $/ \%$ \\
\hline 0 & 199978.99 & 100.00 \\
1 & 199474.39 & 99.75 \\
10 & 194933.32 & 97.48 \\
20 & 189889.63 & 94.95 \\
30 & 184849.91 & 92.43 \\
40 & 179816.15 & 89.92 \\
60 & 174790.34 & 87.40 \\
\hline
\end{tabular}

It can be seen from Table 1 that, when the maximum shearing displacement reaches $60 \mathrm{~mm}$, the shearing area decreases by $15.10 \%$, and the impact on the shear strength calculation has been considerable.

\section{Shear Stress Calculation Correction and Shear Strength Test Analysis}

\subsection{Shear Stress Calculation Correction}

In the direct shear test, the normal stress acting on the sheared soil sample does not increase ${ }^{[11]}$. For the DHJ50-2 stack ring shear tester, when the upper shear box and the lower shear box are staggered by $60 \mathrm{~mm}$ in the direct shear test, the staggered upper shear box soil acts on the widened steel plate at the edge of the lower shear box within the range of the edge steel plate. The area under vertical pressure does not change, and the normal stress also keeps constant if stress deflection is 
not considered. The small friction between the soil sample and the steel plate can be neglected. The shear stress of the soil sample acts on the shear surface of the intersecting part of the upper and lower boxes, and the shear area gradually decreases with experiment continuing. If the shear stress is still calculated with the original area, there will be an error. Based on the above reasons, the calculation of the shear stress needs to be corrected with formula (10).

The shear stress correction formula is:

$$
\tau^{\prime}=\frac{F}{\frac{\arccos \frac{y}{2 R}}{360^{0}} 4 \pi R^{2}-y \sqrt{R^{2}-\frac{y^{2}}{4}}}
$$

In the formula: $\tau$ is the corrected shear stress value $(\mathrm{kPa}), F$ is the vertical load value $(\mathrm{kN})$.

\subsection{Shear Strength Test Analysis}

The coarse-grained soil collected in the Nyang River Valley was sieved to keep the dry density of $1660 \mathrm{~kg} / \mathrm{m}^{3}$, and the soil samples were evenly filled three times. The DHJ50-2 stack ring shear tester is used for the four single-grained, non-water-containing coarse-grained soils. With equal strain loading, the test results are shown in Table 2. The shear strength is calculated with formula (11), and the results are shown in Table 3. The comparison curves of the shear strength before and after correction are shown in Figure 3-Figure 6.

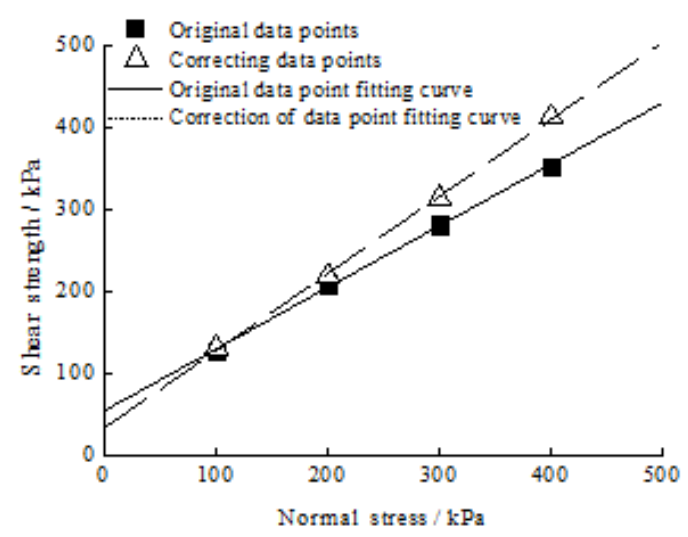

Figure 3 Curve of shear strength of $0.5-1 \mathrm{~mm}$ coarse-grained soil before and after correction.

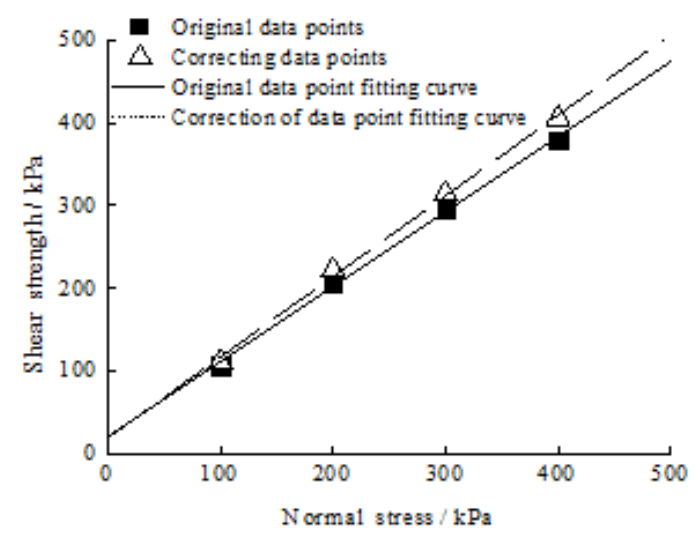

Figure 5 Curve of shear strength of 10-20mm coarse-grained soil before and after correction.

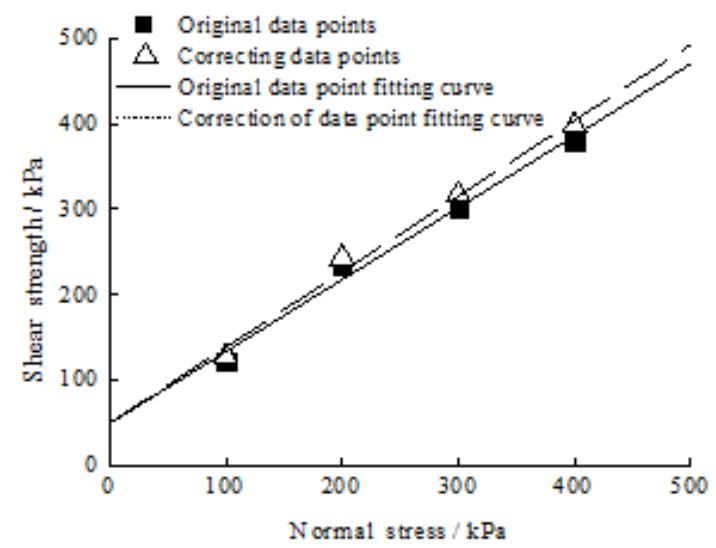

Figure 4 Curve of shear strength of 5-10mm coarse-grained soil before and after correction.

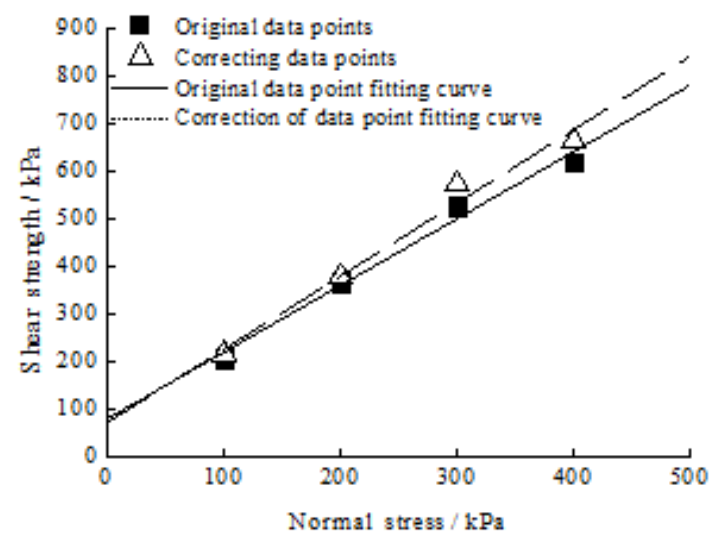

Figure 6 Curve of shear strength of $40-60 \mathrm{~mm}$ coarse-grained soil before and after correction.

Analysis of the results in Table 2 and Table 3 indicates that, before correction, the internal friction angle increases with the increase of the particle size of soil samples, which is consistent with the conclusion in[13]. Shear stress is also in line with this trend. 
Table 2 Direct shear test results of four kinds of homogeneous coarse-grained soils with different particle sizes in Nyang River Valley.

\begin{tabular}{ccccccccc}
\hline & \multicolumn{2}{c}{$100 \mathrm{kPa}$} & \multicolumn{2}{c}{ 200kPa } & \multicolumn{2}{c}{$300 \mathrm{kPa}$} & \multicolumn{2}{c}{$400 \mathrm{kPa}$} \\
$\begin{array}{c}\text { Soil } \\
\text { samples }\end{array}$ & $\begin{array}{c}\text { Horizon } \\
\text { tal load } \\
\text { peak } \\
/ \mathrm{kN}\end{array}$ & $\begin{array}{c}\text { Horizontal } \\
\text { load peak } \\
\text { displacem } \\
\text { ent } / \mathrm{mm}\end{array}$ & $\begin{array}{c}\text { Horizont } \\
\text { al load } \\
\text { peak } / \mathrm{kN}\end{array}$ & $\begin{array}{c}\text { load } \\
\text { peak } \\
\text { displacem } \\
\text { ent } / \mathrm{mm}\end{array}$ & $\begin{array}{c}\text { Horizon } \\
\text { tal load } \\
\text { peak } \\
/ \mathrm{kN}\end{array}$ & $\begin{array}{c}\text { Horizontal } \\
\text { load peak } \\
\text { displacem } \\
\text { ent } / \mathrm{mm}\end{array}$ & $\begin{array}{c}\text { Horizon } \\
\text { tal load } \\
\text { peak } \\
/ \mathrm{kN}\end{array}$ & $\begin{array}{c}\text { Horizontal } \\
\text { load peak } \\
\text { displaceme } \\
\mathrm{nt} / \mathrm{mm}\end{array}$ \\
\hline $0.5-1 \mathrm{~mm}$ & 126.163 & 12.651 & 208.322 & 17.212 & 281.730 & 18.398 & 352.587 & 23.062 \\
$5-10 \mathrm{~mm}$ & 122.613 & 13.326 & 233.975 & 14.442 & 300.782 & 19.851 & 381.240 & 16.422 \\
$10-20 \mathrm{~mm}$ & 106.461 & 11.993 & 207.072 & 20.102 & 295.381 & 23.718 & 379.690 & 17.039 \\
$40-60 \mathrm{~mm}$ & 204.421 & 17.197 & 366.689 & 9.929 & 527.005 & 27.845 & 619.515 & 23.228 \\
\hline
\end{tabular}

Table 3 Calculation results of shear strength of four kinds of homogeneous coarse-grained soils with different particle sizes in Nyang River Valley before and after correction.

\begin{tabular}{ccccc}
\hline \multirow{2}{*}{ Soil samples } & \multicolumn{2}{c}{ Before correction } & \multicolumn{2}{c}{ After correction } \\
Cohesiveness $c / \mathrm{kPa}$ & $\begin{array}{c}\text { Internal friction } \\
\text { angle } \varphi /{ }^{\circ}\end{array}$ & Cohesiveness $\kappa / \mathrm{kPa}$ & $\begin{array}{c}\text { Internal friction } \\
\text { angle } \varphi /{ }^{\circ}\end{array}$ \\
\hline $0.5-1 \mathrm{~mm}$ & 54.031 & 36.9688 & 33.149 & 43.3045 \\
$5-10 \mathrm{~mm}$ & 48.980 & 40.1208 & 49.432 & 41.5506 \\
$10-20 \mathrm{~mm}$ & 20.152 & 42.2394 & 18.808 & 44.3305 \\
40-60mm & 78.088 & 54.5704 & 70.637 & 57.0142 \\
\hline
\end{tabular}

Some domestic and foreign researchers have proposed the concept of nonlinear shear strength for coarse-grained soil ${ }^{[14-17]}$. The results show that the coarse-grained soil conforms to Coulomb's law under low vertical loads, and it is feasible to to analyse the shear strength of coarse-grained soil with Coulomb's law. Combined with the shear strength correction data in Table 3 and the analysis of Figure 3-Figure 6, it can be seen that the corrected internal friction angles of the four kinds of coarse-grained soils are all increased compared with those uncorrected, and the corrected cohesiveness of three kinds of particle sizes are reduced, with that of smaller coarse-grained soil of $0.5 \mathrm{~mm}-1.0 \mathrm{~mm}$ particle size reducing significantly after correction.

\subsection{Shear Stress-Shear Displacement Curve Analysis}

According to the data collected in the experiment, the relationship between the shear stress and the shear displacement before and after the correction is plotted, as shown in Figure 7-Figure 10.

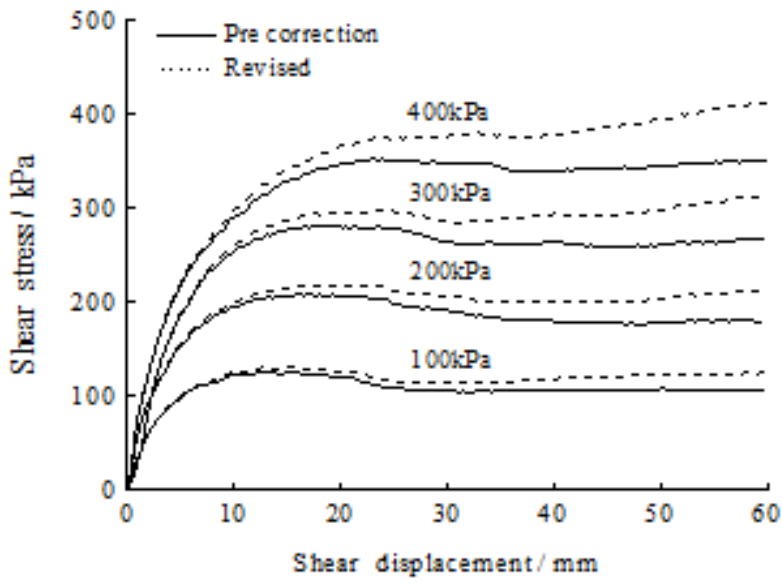

Figure 7 Curve of shear stress-shear displacement of $0.5-1 \mathrm{~mm}$ coarse-grained soil before and after correction.

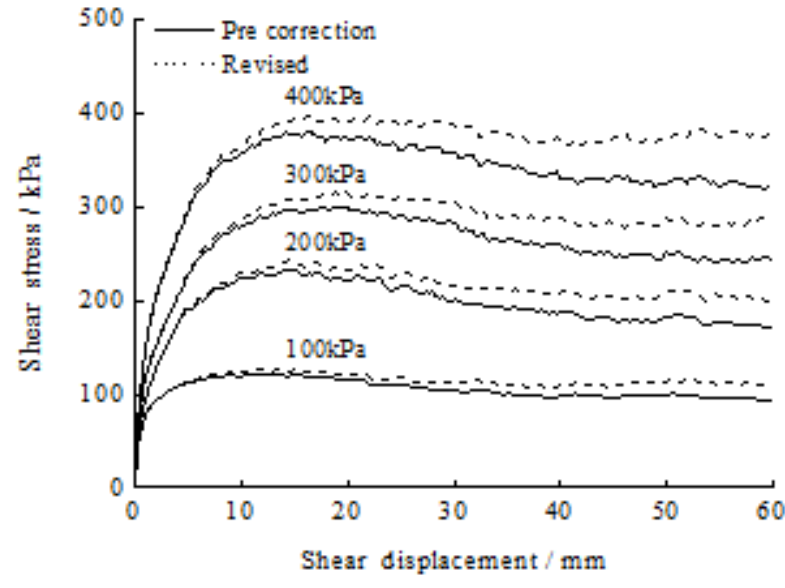

Figure 8 Curve of shear stress-shear displacement of 5-10mm coarse-grained soil before and after correction. 


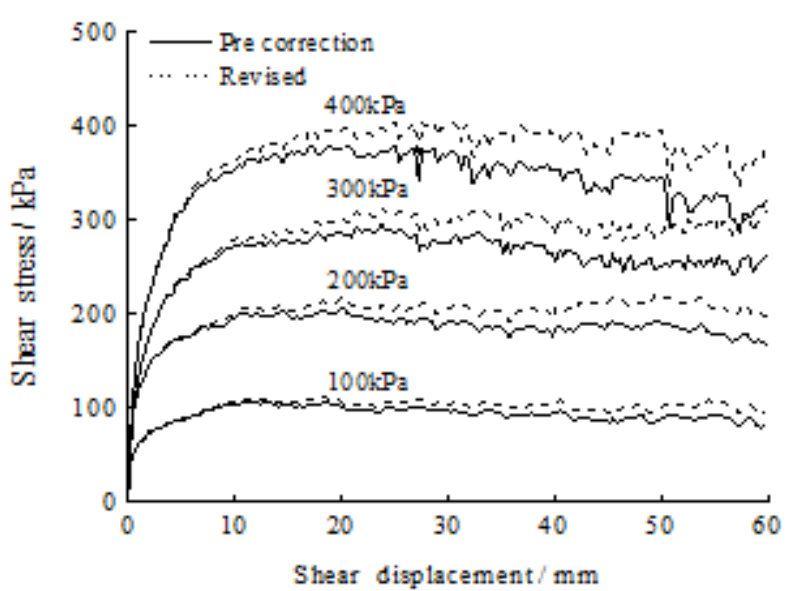

Figure 9 Curve of shear stress-shear displacement of 10-20mm coarse-grained soil before and after correction.

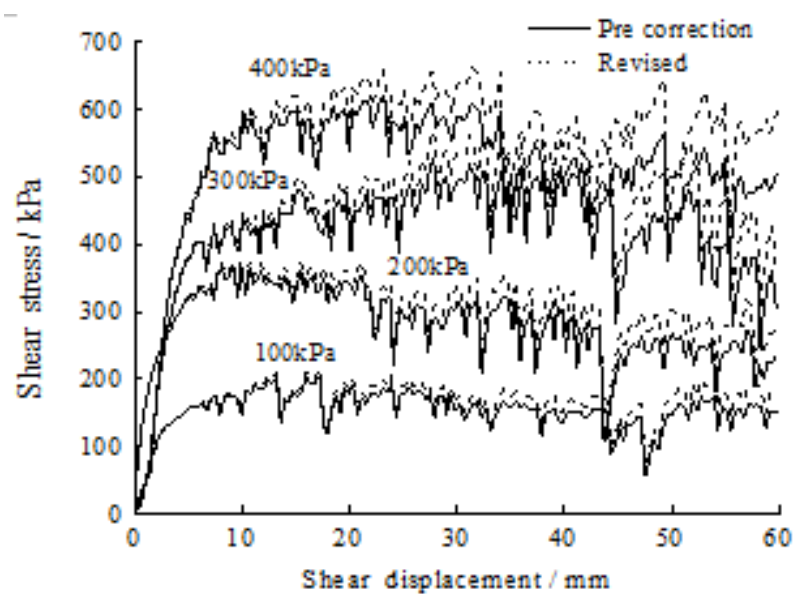

Figure 10 Curve of shear stress-shear displacement of 40-60mm coarse-grained soil before and after correction.

It can be seen form Fig 7-Fig 10 that, with the increase of shear displacement, the shear strength of coarse-grained soil increases rapidly. After entering the peak shear strength region, there is a yield stage similar to steel. The smaller coarse-grained soil of $0.5 \mathrm{~mm}-1 \mathrm{~mm}$ gets hardening in the later period, and the shear strength continues to increase with the increase of shear displacement. Under the higher stress of $300 \mathrm{kPa}$ and $400 \mathrm{kPa}$, the corrected shear strength shows more obvious hardening with the change of shear displacement. At the maximum displacement, the highest shear strength is achieved. In the other three groups with larger particle sizes, after the peak yield stage, softening occurs and the shear strength gradually decreases. The shear strength under the vertical load at all levels is improved after the correction, and the increase is related to the change of the shear area caused by the shear displacement. The smallest grain size of coarse grain soil is $0.5 \mathrm{~mm}-$ $1.0 \mathrm{~mm}$, and at the maximum shear displacement of $60 \mathrm{~mm}$, the corrected shear strength was improved by $17.1 \%$ compared with that before correction; with the increase of particle size, the shear stress fluctuates more severely; the peak of corrected shear strength of the coarse-grained soil with four particle diameters is improved; the peak shear stress changes with shear displacement. After correction, the shearing stress at the peak shear stress of coarse-grained soils with most of the grain size is larger than that before correction, resulting in a backward shift. The statistics of the transitions are shown in Table 4.

Table 4 Statistical table of peak shear stress value of single particle size coarse grained soil.

\begin{tabular}{ccccc}
\hline \multirow{2}{*}{ soil samples } & & \multicolumn{3}{c}{ Normal stress } \\
& $100 \mathrm{kPa}$ & $200 \mathrm{kPa}$ & $300 \mathrm{kPa}$ & $400 \mathrm{kPa}$ \\
\hline $0.5-1 \mathrm{~mm}$ & 1 & 1 & 1 & 1 \\
$5-10 \mathrm{~mm}$ & 0 & 0 & 0 & 0 \\
$10-20 \mathrm{~mm}$ & 1 & 1 & 0 & 1 \\
$40-60 \mathrm{~mm}$ & 0 & 0 & 1 & 1 \\
\hline
\end{tabular}

Note: 1-indicates that the peak of corrected shear stress is larger than the uncorrected one, resulting in a backward shift.

0 -indicates that the peak of corrected shear stress is the same as the uncorrected one, and there is no shift.

\section{Conclusions and Discussion}

(1) The calculation formula of dynamic shear area during the direct shear test was derived, and the dynamic shear area of the soil sample with the change of shear displacement of the DHJ50-2 stack ring shear tester was analyzed with the formula. The analysis showed that soil shear area at the maximum shear displacement decreased by $15.1 \%$ from the initial area. If the shear stress is calculated based on the initial shear area, there will be a big error. 
(2) Direct shear tests were performed on 4 single-grained coarse-grained soils in the Nyang River Valley. The corrected calculation of shear stress was performed with the dynamic shear area formula. The shear stress and shear displacement before and after the correction were compared and analyzed. The results showed that the corrected peak shear stress was higher than the uncorrected one, and the internal friction angle was improved. The cohesiveness (biting force) of most particles decreased, and that of smaller particles decreased significantly; after the correction, the shear displacement of most coarse-grained soils when the shear stress achieved the highest was shifted back; with the increase of particle size, the shear stress fluctuated more violently; the smallest coarse-grained soil with $0.5 \mathrm{~mm}-1 \mathrm{~mm}$ particle size became hardening, and the peak shear stress after correction was achieved at the maximum shear displacement. For soil samples with large particle sizes, there was softening. After the peak of shear stress, the shear strength gradually decreased with increasing shear displacement.

(3) From the curve of shear displacement-shear stress, the peak shear stress occurs during a region. With the increase of particle size, the shear stress jumps very much and has a certain chance. Taking the maximum extreme point directly as the shear strength under the vertical load has certain irrationality. Whether to take the average value of the shear strength within a certain range of the peak region requires further study.

(4) The shear strength of coarse-grained soil before correction is conservative, which is more secure for the project, and there is also a lack of economy.

(5) The mechanism of the hardening of smaller coarser-grained soil and the softening of larger coarse-grained soil requires further study.

(6) The change and mechanism of the friction and bite among particles during the destruction of coarse-grained soil requires further study.

\section{Acknowledgements}

This work was financially supported by "Open Research Fund Project of the State Key Laboratory of Hydrology-Water Resources and Hydraulic Engineering (2016490311)”, "Innovation Support Program for Young Teachers of Universities in Tibet (QCZ2016-48)", "Natural Science Fund Project of Tibet Autonomous Region (XZ2017ZRG-34(Z))", "Graduate Innovation Project of Agriculture and Animal Husbandry College of Tibet University (YJS 2016-11)”. Corresponding author: Zhixiang Cao.

\section{References}

[1] Qingguo Guo. Experimental study on shear strength characteristics of coarse-grained soils[J]. Journal of Hydraulic Engineering, 1987, (5) : 61-67.

[2] Jinlin Zhan, Guohui Lei, Jianyong Shi, et al. Influence of effective shear area on direct shear test results[J]. Journal of Hohai University (Natural Sciences) , 2007, 35 (2) : 213-216.

[3] Haibo Liu, Lihua Zhang, Dachao Lin, et al. Improved calculation of dynamic shear change in direct shear test[J]. Journal of Shenyang Jianzhu University (Natural Science) , 2010, 26 (3) : 503506.

[4] Ministry of Water Resources of the People's Republic of China. SL 274-2001 Design Specification for Rolled Earth Rock Dam[S]. Beijing: China Water Power Press, 2001.

[5] State Bureau of Quality and Technical Supervision, Ministry of Construction of the People's Republic of China. GB 50290-1998 Technical Specification for Geosynthetics Application[S]. Beijing: China Plan Press, 1998.

[6] National Standards Compilation Group of the People's Republic of China. GB/T 50123-1999 Standard for Geotechnical Test Methods[S]. Beijing: China Plan Press, 1999. 
[7] The People's Republic of China Industry Standards Compilation Team. JTG E40-2007 Highway Soil Test Procedures[S]. Beijing: China Communications Press, 2007.

[8] Ministry of Water Resources of the People's Republic of China. SL 237-1999 Soil Testing Procedure[S]. Beijing: China Water Conservancy and Hydropower Press, 1999.

[9] Manchao He. Effective area correction in direct shear test[J]. Opencast Mining, 1986, (2) : 1619.

[10] Minjiang Zhang, Yu Guo, Liping Zhang, et al. A modified method for shear strength of soilin direct shear test[J]. Journal of Shenyang Jianzhu University (Natural Science) , 2005, 21 (2) : 96-98.

[11] Zhiwei Xu, Guoqing Zhou, Zhiqiang Liu, et al. Area correction method and error analysis of direct shear test[J]. Journal of China University of Mining \& Technology, 2007, 36 (5) : 658-662.

[12] Kai Yu, Xin Yao, Yongshuang Zhang, et al. Analysis of direct shear test data based on area and stress correction[J]. Chinese Journal of Rock Mechanics and Engineering, 2014, 33 (1): 118124.

[13] Hong Guo, Zhe Chen. The influence of particle-size on the shear properties of sand and the meso-mechanism[J]. Yangtze River, 2017, 48 (11) : 86-91.

[14] Duncan JM, Byrne P, Wong KS, et al. Strength, stress-strain and bulk modulus parameters for finite element analysis of stress and movements in soil masses[J]. Journal of Consulting \& Clinical Psychology, 1980, 49 (4) : 554-67.

[15] Mello V F B D. Reflections on design decisions of practical significance to embankment dams [J]. Géotechnique, 1977, 27 (3) : 281-355.

[16] Jiayu Yin, Anning Lai, Pu Jiang. Strength and deformation characteristics of tailings sand under high pressure[J]. Chinese Journal of Geotechnical Engineering, 1980, 2 (2) : 22-28.

[17] Qingguo Guo. Engineering characteristics and application of coarse-grained soil[M]. Zhengzhou: Yellow River Conservancy Press, 1998. 